THE HOST PROGRAM AND SOCIAL INCLUSION

by

Zebiniso Abduvaitova, BA, National University of Uzbekistan, 2003

\author{
A Major Research Paper \\ presented to Ryerson University \\ in partial fulfillment of the requirements for the degree of \\ Master of Arts \\ in the Program of \\ Immigration and Settlement Studies
}

Toronto, Ontario, Canada, 2010

(C) Zebiniso Abduvaitova 2010 


\section{Author's Declaration}

I hereby declare that I am the sole author of this major research paper.

I authorize Ryerson University to lend this paper to other institutions or individuals for the purpose of scholarly research.

Signature

I further authorize Ryerson University to reproduce this paper by photocopying or by other means, in total or in part, at the request of other institutions or individuals for the purpose of scholarly research. 


\title{
THE HOST PROGRAM AND SOCIAL INCLUSION
}

(C) Zebiniso Abduvaitova, 2010

\author{
Master of Arts \\ Immigration and Settlement Studies \\ Ryerson University
}

\begin{abstract}
This study examines the role of the Host Program in the social inclusion of newcomers into Canadian society through formation networks and ties with the mainstream community. With the help of qualitative methods, this study seeks to investigate whether participation in the Host Program facilitates building networks and ties among newcomers and host Canadians. The findings suggest that the Host Program facilitates the development of networks and ties with the host society, with the volunteers being the main structured opening into the mainstream group. Informal and friendly interactions with host volunteers give newcomers a much needed sense of confidence and comfort, which in turn enables them to access and benefit from other existing services and make friends outside of their own communities. This research concludes that the Host Program is indeed effective in expanding networks and building ties to mainstream society and, potentially, in the social inclusion of newcomers into the receiving society.
\end{abstract}

\section{Key words:}

Host Program; social inclusion; social capital; networks; settlement 


\section{Acknowledgements}

The completion of this major research paper could not have been possible without the continuous encouragement, patience, and help of Dr. Myer Siemiatycki, who provided his guidance and support as my supervisor throughout the writing process. I am deeply grateful for this.

I would also like to thank Dr. Arthur Ross, my second reader, for providing his insightful suggestions which helped improve this paper considerably.

The successful completion of my studies in Immigration and Settlement Program would not have been possible without the loving support of my husband and son.

Finally, I would like to thank the six participants who kindly shared their experience. Without them this study would not have been possible. 


\section{Table of Contents}

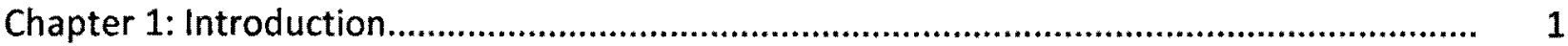

Setting the context: Settlement Services and Settlement Programs................................. 2

Research Problem.....................................................................................................

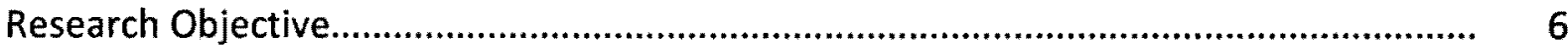

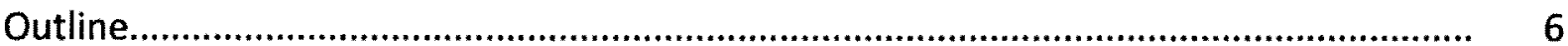

Chapter 2: Theoretical Framework........................................................................................... 8

Social Inclusion, Social Networks, Social Capital and the Host Program............................ 8

Chapter 3: Literature Review........................................................................................... 15

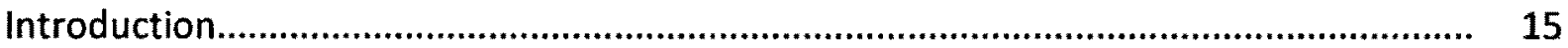

Canada's Approach to Settlement and Integration....................................................... 16

Host Program: What is known?

Lack of Promotion and Lack of Funding....................................................................... 27

Disconnect Between Immigrants Information Gathering Practices and Information

Providing Practices by Settlement Agencies...................................................................... $\quad 29$

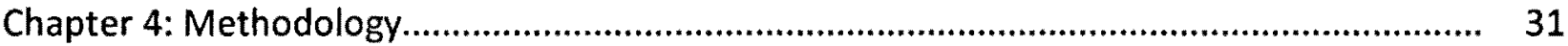

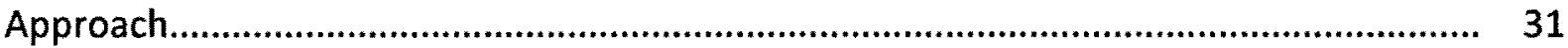

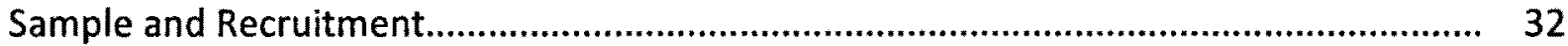

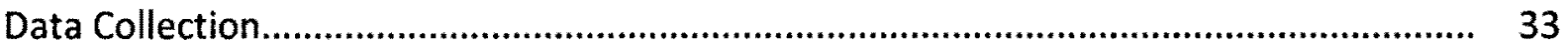

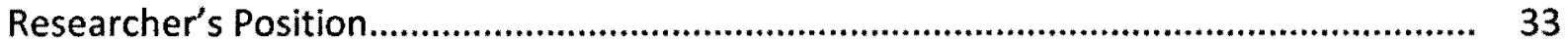

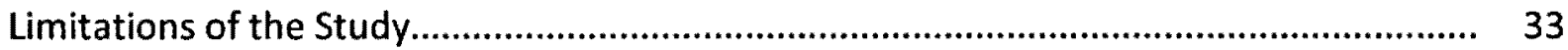

Chapter 5: Research Findings, Discussion and Conclusion....................................................... 35

Effectiveness of the Host Program in Adaptation and Integration of Newcomers............ $\quad 35$

Impact of the Host Program on Newcomers...................................................................... 37

Impact of the Host Program on Volunteers................................................................... 43

Funding and Promotion.................................................................................................. 49

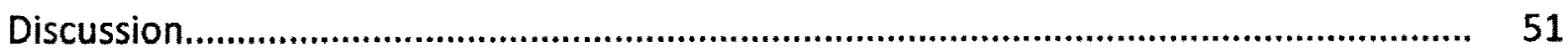

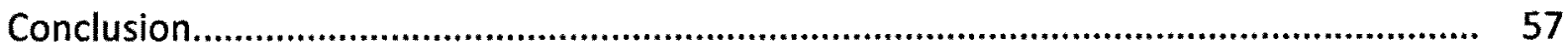

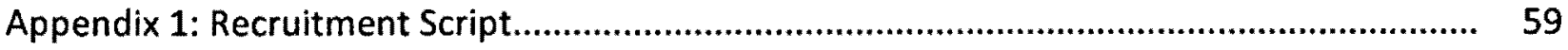

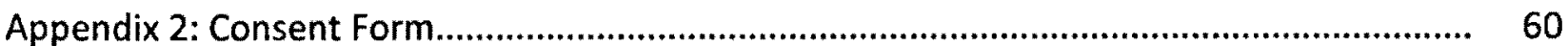

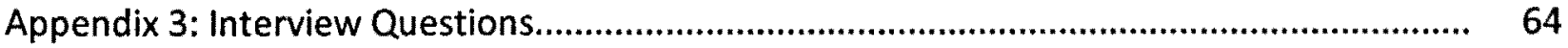

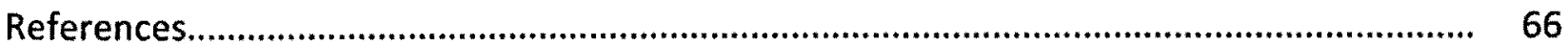




\section{Chapter 1}

\section{Introduction}

Canada is a country of immigrants. Every year, around 250000 immigrants arrive in Canada and, today, immigrants comprise almost $20 \%$ of the Canadian population. There are three main categories under which Canada accepts immigrants: economic class, family class and refugees (George, 2002). It is obvious that immigrants constitute a significant part of Canadian society and its economy and, therefore, the successful integration of newcomers is of great benefit to both the host society and immigrants themselves. However, despite the high level of education and skills of newcomers, there has been a dramatic decline in economic wellbeing among recent immigrants. This phenomenon has been well documented by numerous researchers, including Pendakur (2000), Ornstein (2000), Galabuzi (2001), Mwarigha (2002), and Shields (2002) (cited in Omidvar and Richmond, 2003). Interestingly, some authors have argued that improving and expanding the economic and social opportunities of immigrants is strongly related to the networks that immigrants build in their new country (Kunz, 2003, Beugelsdijk and Smulders, 2003). Undoubtedly, finding employment is a crucial part of integration and settlement; however, it does not address all the needs of immigrants. In addition to finding a job, newcomers need to find a welcoming and safe place to live and need to learn to adapt to the Canadian way of life. Not only are immigrants our co-workers, they are also our neighbours, friends and community members (Kunz, 2005). Therefore, settlement services that assist newcomers in their adaptation to a new country are of vital importance to the entire settlement and integration process. There are three main settlement programs funded by the 
federal government through Citizenship and Immigration Canada (CIC): The Immigrant Settlement and Adaptation Program (ISAP) the Language Instruction for Newcomers to Canada (LINC) and the Host Program. The Host Program is most explicitly directed at building relationships between newcomers and the host population. It is the Host Program that is of interest to this study. However, for the purpose of setting the context, in the next chapter I will provide a detailed overview of the three major settlement programs.

\section{Setting the Context: The Settlement Sector and Settlement Programs}

Settlement services have a long history in Canada. Before the First World War, there were a very small number of organizations that specialized in immigrant services. Mainly, they were informal services in which newcomers were assisted by family members, friends, ethnic associations, churches and groups of people, the majority of whom were volunteers. After the First World War several immigrant helping organizations were formed, such as the Jewish Immigrant Aid Society, which was created in 1922. However, it was not until after the Second World War when significant improvements were made in the delivery of settlement services. One of the main reasons was the arrival of the large number of Jewish refugees coming to North America after World War II. The Jewish Immigrant Aid Society was among the first to employ professional social workers in order to facilitate the delivery of specialized settlement services to newcomers (National Settlement Conference 2, 2003). The Settlement Service sector was established in 1948 when federal settlement officers were placed throughout the country to assist war refugees and families of Canadian soldiers to adapt to life in Canada. Today, Canada has one of the most enhanced and comprehensive settlement and integration models in the world. It helps newcomers to adapt, settle and integrate into Canadian society as 
quickly and comfortably as possible. There are three major settlement programs funded by the federal government: LINC, ISAP and the Host Program.

LINC is a federal language training program aimed at providing the basics of English and French language to newcomers. The program is free and is available to anyone within his/her first 3 years in Canada. It is provided directly in communities and has full-time and part-time options to choose from. Child care, offered in many locations, is a significant form of aid being offered to immigrants with small children. As a part of its broad integration program, LINC's curriculum goes beyond the basic teaching of languages and incorporates different orientation and assistance services, also providing education on topics such as Canadian history and culture, rights and laws, society and community. Some global international issues, such as human rights, hunger and disasters are also covered. Overall, LINC does a good job in teaching and providing newcomers with insights into the new world (CIC website, 2010).

ISAP is another federally funded settlement program that assists immigrants with the settlement and integration process. Unlike LINC and HOST, ISAP is a more employment oriented program which provides direct services to new immigrants, such as information and referral services, orientation, translation and interpretation, solution-based counselling and assistance with searching for jobs. ISAP counselling services also help new immigrants with their immediate settlement needs, such as health care, transportation, housing and education. Services are delivered both on a one-to-one basis and through the provision of group services (Integration Branch of CIC, 2001).

The Host Program is fundamentally different from the other two programs, in that immigrants receive integration services not from professional counsellors, teachers or social 
workers, but from Canadian volunteers who want to assist new immigrants with their integration into Canadian society. It is a friendship-based program, host volunteers help newcomers by providing moral support, help them practice English or French, direct immigrants to existing services, include them in social events and introduce them to their networks of friends. At the same time, it is beneficial for Canadian volunteers, as they also make new friends, learn about other cultures, traditions and countries (CIC, Welcome to Canada Brochure, 2007). Organizations that are funded to provide Host Program services have to perform a variety of tasks:

- promote the program;

- recruit, select and train volunteer hosts;

- match newcomers with hosts based on mutual interests;

- monitor and support the newcomer-host relationship;

- evaluate the program and report to $\mathrm{CIC}$ on program activity.

The Host Program has five desired outcomes, but three of them overlap with the outcomes of LINC and ISAP. The outcomes include:

- Newcomers can communicate in the language of settlement

- Newcomers can access community services like libraries and education and health care facilities;

- Newcomers can improve their access to employment and education

The two outcomes that distinguish the Host Program from the ISAP and LINC include:

- Host communities, through specially trained volunteers, welcome and engage newcomers; and 
- Newcomers, through interactions with host volunteers are engaged in diverse social networks in host communities (Anisef et al, 2007).

In other words, the main characteristics of the Host Program lie in the area of community engagement, social capital and social networks.

\section{Research Problem}

The Host Program is the smallest settlement program. It is the least funded, when compared to LINC and ISAP. For example, in the 2007-2008 fiscal year its budget was $\$ 10 \mathrm{~m}$, while LINC received $-\$ 174,7 \mathrm{~m}$ and ISAP $-\$ 173,6 \mathrm{~m}$ (Biles, 2008). Also, I was able to locate the numbers of immigrants served by these three major settlement services for the 2005-2006 fiscal year. According to the Audit of Immigration final report for 2007 LINC served 91,672 newcomers and ISAP 82,794 , while the Host program provided services for only 5,184 new immigrants. The dramatic difference between these numbers clearly reflects evidence that the Host program is not being used to its full potential and is not being emphasized enough, given its potential impact on acquiring social networks and its necessity for the successful integration and settlement of newcomers (George and Fuller-Thompson, 1997). It is hard to disagree that the extensive and wide circle of social networks provided by the host society will potentially lead to a better social inclusion of new immigrants into Canadian society. Therefore, given that the main outcomes of the Host Program relate to social networks and community engagement, I argue that the Host Program is an undervalued settlement program for achieving social inclusion. My belief is that if the Host Program is provided to more immigrants it will benefit not only immigrants themselves, but society as a whole. Having said this, I was struck by the 
limited amount of research available on the Host Program in general and, in particular, by the virtual absence of research discussing it from the social inclusion and social capital perspective ${ }^{1}$.

As this study explores the Host Program from the social inclusion and social capital perspective, the next section is devoted to building a theoretical framework of these notions around the Host Program, which is directly aimed at building social ties and networks with the broader community.

\section{Research Objective}

As the ultimate goal of settlement programs in Canada is to support the full and equal participation of immigrants in the economic, social, cultural and political dimensions of life in their new country, the key objective of this study is to develop a critical understanding of the role of the Host Program and its contribution to the social inclusion of newcomers into the host society. Specifically, this study will determine the role that the Host Program plays in the process of successful integration of immigrants into Canadian society and whether the social capital of newcomers is enriched and expanded through participation in the Host Program, and whether this, in turn, leads to a better social inclusion of newcomers into Canadian society. The answers to these questions may help us to better understand the role, if any, that the Host Program plays in the social inclusion of newcomers into Canadian society.

\section{Outline}

This research begins with an introduction to the theoretical notions of social inclusion and social capital and how they relate to the goals and objectives of the Host Program. Next, I

\footnotetext{
${ }^{1}$ An exception is Kunz's (2005) discussion paper where she argues that settlement programs like the Host Program facilitate better social and economic integration of newcomers through the development of social networks between newcomers and receiving society.
} 
will discuss Canada's approach to immigrant settlement and integration in order to provide a complete picture of the settlement sector in Canada. Then, I provide a review of the current literature, which will specifically discuss the Host Program and the challenges and issues related to the delivery of the program. In the following chapter I will present the findings regarding the experiences of newcomers and Host volunteers with the Host Program. The paper concludes with a summary of the main findings. 


\section{Chapter 2}

\section{Theoretical Framework}

\section{Social Inclusion, Social Capital, Social Networks and the Host Program}

The integration of immigrants is not about simply helping them to find a place to live and work. It extends far beyond that and involves the assistance, in part, of the receiving society to help them understand the culture, norms and values of the host society. $\mathrm{CIC}(2001)$ defines successful integration as the ability of immigrants to freely contribute to the economic, cultural, political and social aspects of life in Canada. For me, an example of successful integration is when immigrants feel included in all aspects of life in the host society. I believe that this feeling stems from the presence of networks and ties that immigrants have, not only with their own ethnic communities, but also with mainstream society. Recent research suggests that a strong basis for the effective integration of immigrants into mainstream society depends on building mutual support and solidarity within communities, and that cultural differences between immigrants and mainstream society in itself does not hinder successful integration (Banting et al. 2006, Berry et al. 2006, Banting and Kymlicka, 2006, Harty and Murphy, 2005 cited by Galabuzi and Teelucksingh, 2010). Moreover, as Florida (2002) has suggested, diversity can be a key positive value which offers creative energy and new ideas for the community building process. It is only natural to assume that the recognition of cultural diversity and ensuring a sense of dignity for diverse immigrant groups benefits all members of a host community.

In this study I will use the notions of social inclusion and social capital as the theoretical frameworks which most enrich the Host Program and will allow us to see its contribution to the 
integration and settlement of new immigrants to Canada from different perspectives. The research hypothesis that I am putting forward in this study is that the Host Program, by expanding networks and enriching the social capital of newcomers, can considerably increase the level of social inclusion of newcomers in Canadian society. This, in turn, may lead to better outcomes in the social, cultural, economic and political spheres of life of newcomers and society as a whole. This hypothesis corroborates with the findings of Reitz's (1998) comparative study of Canada, the U.S. and Australia, in which he states that the "level of public support for settlement is vital to immigrants' economic success and socio-political inclusion" (Reitz, 1998, cited in Omidvar and Richmond, 2005).

Canada has one of the highest proportions of immigrants and therefore, it is highly important for the nation to develop successful mechanisms for the social inclusion of newcomers into Canadian society. This is especially crucial in light of recent findings that show that the consequences of social exclusion affect not only those who are excluded, but also wider society and the economy in general (Warchauer, 2002 cited by Caidi and Allard, 2005). In this regard Qadeer and Kumar (2006) suggest that building social relationships and networks of immigrants can be potential solutions to improving immigrants' economic and social well-being, which in turn benefits society as a whole. Indeed, studies on the integration and social capital of immigrants have demonstrated a strong correlation between the networks that immigrants form in a host society and economic well-being (Der Martirosian, 1997, Aguilera, 2003 cited in George and Chaze, 2009). The economy component is crucial as economic integration is one of the most important factors for people immigrating to Canada and one of the most immediate needs of immigrants remains employment (Kunz, 2005). 
The term social inclusion is highly contested: it is differently understood, interpreted and applied by various authors. It means different things to different people can be defined in various ways and can serve a variety of purposes (Siemiatycki, 2005). However, for the purposes of this study I will use neutral, descriptive definitions, such as Peter Robinson's, who defines social inclusion as a "situation where everyone is able to participate fully in society and no-one is blocked from doing so by political and civil rights, by lack of employment or income, by ill-health or lack of education" (Robinson, 2000, 154) or Sen's (2001) who characterizes social inclusion "by society's widely shared experience and active participation, by a broad equality of opportunities and life chances for individuals and by the achievement of basic level of well-being for all citizens" (cited in Omidvar and Richmond, 2005).

The notion of social inclusion first originated in France in 1970 in response to a crisis in welfare and health care systems. It first targeted the growing number of people experiencing long-term poverty and long-term unemployment. Later, when the concept gained credibility throughout Europe, it started to include "non-traditional" target groups, such as people with disabilities, the elderly, racial minorities and embraced a wide range of socio-economic problems, including unemployment, poverty and declining health and education levels together with high crime rates, inter ethnic and racial polarization (Omidvar and Richmond, 2005, 166; Siemiatycki, 2005). This, in turn, determined the multi-dimensional approach of social inclusion, which can be developed in different directions. Omidvar and Richmond have identified three main directions in which the notion of social inclusion can be developed. The first approach would focus on the incorporation of the principles of equity and access to a conventional agenda of universal social inclusion. This approach would see the problem of exclusion resolved by 
increasing access to the entitlement of the raditional post-war welfare state. The second approach would target traditionally marginalized populations, such as the unemployed, people with disabilities, racial and ethnic minorities, the homeless, etc., through capacity building and focusing resources on those who are most in need. The third approach would be a "rightsbased approach" which emphasizes the need for a policy that ensures that everyone has the ability and opportunity to be included (Omidvar and Richmond, 2005). The authors believe that a multidimensional approach would make it possible to successfully deal with the problems of social exclusion and promote social inclusion.

Galabuzi and Teelucksingh $(2010,34)$ also state that a "systematic and systemic approach to social inclusion and social cohesion is essential to addressing social exclusion and effectively utilizing social capital as a resource for social, economic, and community development". In the Canadian context, social inclusion is reflected in the national agenda of multiculturalism. It states that the Canadian government's policy is to "promote the full and equitable participation of individuals and communities of all origins in the continuing evolution and shaping of all aspects of Canadian society and assist them in the elimination of any barrier to that participation" and to "ensure that all individuals receive equal treatment and equal protection under the law, while respecting the value of diversity" (Canadian Heritage, 2004 cited in Caidi and Allard, 2005, 4).

If social inclusion, in the Canadian context, means the equal and full participation of both hosts and immigrants in all aspects of Canadian society, it implies that those who participate together have established relationships and networks with each other. Otherwise, equal participation seems to be impossible. Therefore, social inclusion requires the creation of 
networks and ties between newcomers and the host society. In this, the role of the Host Program is crucial. As mentioned above, the main outcomes that distinguish the Host Program from LINC and ISAP relate to social networks and social capital. Therefore, exploring the concept of social capital is a must for this study.

Social capital is a broad term that can be applied in many different contexts (PRI, 2003) therefore, it is important to specify that, for the purposes of this study, I will be discussing the role of social capital in the integration and settlement of newcomers to Canada. Before doing so, however, I will provide some clarification of the term itself.

Just as in the case of the term social inclusion, there is no generally accepted definition of the term 'social capital'. However, in most of the definitions, social capital is defined in terms of social networks. There are also a number of common characteristics in definitions of social capital, such as: norms, values and trust (Beugelsdijk and Smulders, 2003; Kunz, 2005). The social capital field is divided into two approaches - functional and network-based. The most relevant approach to this study is the network-based one which argues that social capital consists of "networks of social relations that provide access to needed resources and supports" (PRI, 2003). Caidi and Allard (2005) describe social capital in terms of group of people with shared norms, values and understanding that assist cooperation within or among groups. In other words, social capital is about "benefit accrued from relations among persons" (Coleman, 1988 cited by George and Chaze, 2009, 266). As a result, the key feature attributed to social capital is that it exists in the relationships among groups and individuals (Coleman, 1988 cited by Kunz, 2005). 
Social capital also refers to the networks individuals belong to and from which

individuals get benefits through knowing others and with whom they form networks (Nahapiet and Goshal, 1998 cited by Beugelsdijk and Smulders, 2003). In general, there are two types of social networks described in the literature. The first one, formed within homogenous groups like family, friends and other people of the same ethnic, socioeconomic status and cultural background, is called a bonding network or closed network. The other one is named a bridging network or open network and involves forming relationships with people from different ethnic, cultural and socioeconomic groups (Beugelsdijk and Smulders, 2003, Kunz, 2005, PRI, 2003, Galabuzi and Teelucksingh, 2010). Bonding networks are of primary importance in the early stages of accommodation, when newcomers are becoming familiarized with their new environment. Bridging networks, in turn, are more important in the later stages of accommodation, as they allow newcomers to access resources that are otherwise not so easily accessible via bonding types of networks. It is bridging networks that, in most of the cases, determine how well immigrants get ahead in Canadian society in different aspects of life (Kunz, 2005; Beugelsdijk and Smulders, 2003). Thus, it is evident that bridging networks directly relate and underscore the distinctive characteristics of the Host Program in that it allows for the establishing of ties between newcomers and the receiving society.

It has also been argued that the better one's social capital, the greater the chances of integration into society (Caidi and Allard, 2005). Social networks are the form of social capital which has been most directly attributed to the successful integration of immigrants. In this regard, the Host Program has been identified as a key tool in building linkages to the broader community (Kerr and Powers, 2005). According to Kerr and Powers' (2005) findings from their 
"Review of Host Group Service Models in Ontario" conducted for CIC, facilitating the development of social networks is a primary objective for most Host Program service agencies. This objective includes developing friendships, making connections to informal networks, helping newcomers to meet new people from their local communities, learning how to befriend Canadians, and so on. It is quite natural to assume that it is always easier to enter into a certain community if your entrance is being facilitated by one of the members of the community. This is exactly what the Host Program aims to deliver to newcomers - facilitation of participation in the life and social events of their local communities. This, in turn, considerably enhances social networks and may lead to the social inclusion of new immigrants into their new communities.

I believe that settlement services such as the Host Program can be the key agents in facilitating and promoting social networks between new immigrants and host communities. In turn, strong networks and well-established relationships between immigrants and mainstream society may result in the better social inclusion of immigrants into Canadian society. As discussed below, the role that the Host Program plays in this process is of particular importance. 


\section{Chapter 3}

\section{Literature Review}

This chapter begins with a discussion of the Canadian approach to the settlement and integration of new immigrants. This discussion will provide the context and framework within which major settlement programs are developed and delivered. Next, I give background information about the Host Program: its history, development and evolution. Further, this chapter aims to review the current literature on the Host Program. Unfortunately, as I already mentioned, there is very limited academic literature available and only one article discusses the Host Program from a social capital and social inclusion perspective. Therefore, in this section I will be drawing on the Host Program Conference working papers from the Host Ontario website, the Evaluation of Host conducted by $\mathrm{ClC}$ and several articles I was able to locate related to the Host Program. The main objective of this literature review is to identify what has been written about the Host Program and which perspectives it was discussed from. In last section I will also discuss some of the main issues hindering the effectiveness of the program which I have been able to identify from the literature.

\section{Introduction}

Settlement and adjustment to a new country is a very challenging and arduous task especially if one does not have someone to help him/her navigate through the transition period, which is often accompanied by stress and a state of cultural shock (CIC, 2004). Therefore, being assisted by a friendly, helpful and welcoming Canadian resident, who provides social support and networking and most importantly, who has been specially trained for this 
reason, can make this transition period less stressful and less traumatic (Baldacchino et al, 2009).

Before focusing the discussion on the Host Program as an important part of Canadian settlement services, I would like to give a general overview of the Canadian approach to the settlement sector. This will help us to situate the Host Program within the broad settlement and integration approach that the Canadian government adheres to. Comparative analysis with the U.S. settlement approach will also be used in order to better assess the methods used in Canada.

\section{Canada's approach to settlement and integration}

What we are seeing now as the Canadian settlement sector was very different several decades ago. Prior to the 1950 s it was virtually nonexistent, as the primary concerns of immigration officials were mainly centred around recruitment, screening and processing issues (Bloemraad, 2006). This, of course, does not mean that immigrant's did not have settlement and integration needs prior to the 1950s. This only means that a centralized and coordinated approach was not in place to address those needs. As previously mentioned, the settlement needs of newcomers were addressed in informal ways by friends, family members and religious institutions. The formal settlement sphere started to evolve and develop with the establishment of the Department of Citizenship and Immigration in 1950. It was at this point that the number of services, such as language training, employment services, citizenship classes and health and welfare assistance started to be made available to newcomers. After the initial stages, the federal government played a major role in establishing integration and settlement 
policies in Canada by explicitly recognizing, in the Immigration Act of 1976, the importance of integration as a benefit for the country (Bloemraad, 2006).

The general framework within which all integration takes place in Canada is reflected in section 3 of the Immigration and Refugee Protection Act: "(e) to promote the successful integration of permanent residents into Canada, while recognizing that integration involves mutual obligations for new immigrants and Canadian society" (cited in Biles, 2008, 140). This framework explicitly acknowledges the mutual responsibilities of both newcomers and hosts in building an inclusive and cohesive society. This endeavour is well illustrated by the fact that the integration of immigrants in Canada is not restricted to only one department or agency within the government; in fact, it includes all levels of the government and community organizations, such as the United Way, as the main funders and coordinators, with the federal government playing a major role. However, governments are not the only key actors in immigrant settlement and integration in Canada. The immediate service provision to immigrants is accomplished by a variety of societal actors, including service providing organizations (SPOs), ethno-racial, religious organizations, multicultural organizations, educational institutions and even partners in the private sector (Biles, 2008; Bloemraad, 2006).

Delivery of services through third parties is one of the main characteristics that distinguish the Canadian approach to integration from that of many other countries. These third-party organizations form a strong non-governmental sector and work in close partnership with the governments; a vivid illustration of what Biles (2008) calls 'societal endeavour'. There are also a number of differences that make the Canadian approach, compared to other countries, so generous and comprehensive. For example, when the U.S. Congress passed the 
first federal legislation directed at assistance to refugees in 1962, Canada had already relatively established the settlement sector with almost 200 immigration officers and settlement workers engaged in assistance to newcomers across the country (Bloemraad, 2006). Two other important characteristics that distinguish the Canadian approach to integration and settlement from that of the U.S. include: first, in Canada, every category of immigrants is covered by settlement support programs, whereas American settlement programs are exclusively focused on refugees and are not available to other immigrants. According to Bloemraad (2006) this kind of discrimination stems from the assumption of the U.S. government that, since immigrants gain permanent residency through employment preferences, they therefore possess the skills necessary for unassisted adaptation and integration. The Canadian government's policy, on the other hand, was clearly articulated in the Immigration Act of 1976 where the settlement and integration of newcomers was recognized as important for the 'domestic and international interests of Canada'. Therefore, the second characteristic that distinguishes the Canadian approach from the U.S. approach is that in Canada, the government plays an active role and has so called 'interventionist' policies to support the settlement of all categories of immigrants.

Having already discussed the benefits of the Canadian multi-level approach to settlement and integration, it is also important to acknowledge its challenges. The multi-level structure of funding, coordination and service provision has won Canada a reputation as one of the most immigrant welcoming countries in the world. However, such a complicated scheme is inevitably accompanied by its own challenges. Biles (2008) has identified four the most important: coordination, information sharing practices, continuity and evaluation. Indeed, given its complex nature, ensuring the coordinated and collaborative work of key players seems to be 
one of the biggest challenges to the Canadian approach. Getting comprehensive and relevant information about the available services seems to be a challenge as well. Also, there is no generally accepted approach among major stakeholders as to how to reach immigrants. Continuity refers to the instability of government-funded initiatives and to funding problems themselves. Evaluation of the effectiveness of existing services and their relevance to the needs of immigrants is unquestionably another serious challenge that has yet to be addressed.

In defining integration, the Canadian government puts a strong emphasis on mutual obligations in the adjustment process. As CIC $(2001,4)$ defines it:

Integration is a gradual process that requires an active commitment from both newcomers and the receiving society" ... "Newcomers are expected to understand and respect basic Canadian values, and Canadians are expected to understand and respect the cultural differences newcomers bring to Canada. Rather than expecting newcomers to abandon their own cultural heritage, the emphasis is on finding ways to integrate differences in a pluralistic society.

This emphasis underscores the role of the Host Program in integration and settlement, as its main goal is to connect newcomers with Canadians and to ensure mutual work in building a more inclusive society. In light of this vision of integration, it is not clear why the Host Program has always been, and remains, the least funded program. Unfortunately, within the scope of this paper I will not be able to fully address an important issue regarding the stark contrast in funding that I outlined in a previous chapter. However, I will be able to suggest some thoughts on how and why this funding situation emerged. The historical context might offer us some kind of understanding of this issue.

Historically, Canada has put a strong emphasis on the economic side of integration, as it believed, and rightly so, that stable and reliable employment ensures successful integration. 
This resulted in allocating most of the budget to employment related services from the very beginning of the settlement sector's emergence (Bloemraad, 2006). Next, language training is also undoubtedly an integral part of labour-market integration, because it is impossible to find a stable job without language proficiency. This led to allocating most of the budget towards the employment and language needs of newcomers. Kunz (2005) in her discussion paper echoes this by stating that language and employment are the top priorities in settlement and integration. As she puts it:

We must remember that people immigrate to Canada primary for economic and educational reasons. The immediate needs of newcomers remain language; employment, housing, and access to other social services. Understandably, programs that require the bulk of government funding are LINC and ISAP (Kunz, 2005, 16).

I completely agree that language and employment are crucial parts of settlement and integration; however, that being said, I believe that the social and cultural sides of integration are no less meaningful. I think that the insufficient attention being given to Host-like services stems from the fact that issues of social inclusion and social cohesion have started to draw serious attention only relatively recently with the change in racial composition of immigrants from predominantly white to more diverse, non-white immigrants. Prior to 1967, Canada's immigration policies were rather discriminatory regarding race, ethnicity and country of origin. The points system introduced in 1967 changed the situation entirely. Immigration was no longer a privilege, but rather a right granted on the basis of points awarded for certain skills and experience. Criteria like race, nationality, and country of origin were no longer of principal importance (Kelley \& Trebilcock, 2000). Therefore, language, traditions and culture were not 
the biggest challenge for the immigrants with mostly Anglo-Saxon backgrounds which comprised most of the immigration prior to the adaptation of the point system.

It is probably the increased proportion of non-white immigrants with completely different cultural, religious, traditional and language backgrounds that caused the problem of social inclusion to come into play. I am not calling for increased funding for the Host Program at the expense of reducing funding for employment assistance and language training. I fully acknowledge the importance of language proficiency and employment assistance services for successful integration. What 1 am recommending is giving increased attention, and, most importantly, funding to the no less crucial parts of settlement - social and cultural integration. Growing evidence on the mismatch between high education levels and skills and poor economic outcomes of recent immigrants (Shields, 2007) probably points in the same direction. Therefore, there is obviously a need for more attention to be paid to the social and cultural integration of newcomers, so that they are able to participate fully in all aspects of life in their new country and Host Program is an ideal tool for this.

The Host Program was first introduced in 1985 by the Canadian government and was initially designed as a community-based service for sponsored refugees. After the results of a study conducted by Employment and Immigration Canada in 1986 which showed that newcomers assisted by community support systems settled more quickly, the Host Program was extended to all immigrants. The Program facilitates the integration of newcomers by matching them with Canadian volunteers who help them to adapt to their new life in Canada. They help to overcome the language barrier, search for jobs, and become familiar with the transit system, grocery stores, banking and other everyday activities. Because it is the only 
volunteer-based settlement program, the Host Program effectively facilitates and supports the integration and settlement of newcomers by establishing friendships between newcomers and Canadian residents (CIC, 2010). Activities are designed to enhance the newcomers' crosscultural understanding and encourage community participation and integration. In return, Canadian volunteers make new friends, learn about other cultures and contribute to community life. Simply put, the Host Program is all "about friendship offered and given, and friendship received and returned" (CIC, Welcome to Canada Brochure, 2007). There is clear evidence of the demand for this kind of service, as in the last couple of years the Host Program has expanded significantly and is now delivered by 45 service provider organizations, compared to 25 in 2007-2008 (Axiom Consultants Inc, 2009). It also increasingly involves group activities with volunteers or staff members facilitating conversation circles, cooking groups, homework clubs and other activities. Also, in recent years, the number of Host service providing organizations has started to become more specifically targeted towards special populations such as youth (Anisef, 2005).

As the Host Program facilitates and supports the integration and settlement process of newcomers in Canada through direct involvement of members of the host society one can rightly say that the Host Program is the only settlement program that reflects the 'two-way street' integration model, as it engages Canadians in the integration process by connecting newcomers with Canadians (Biles and Winnemore, 2006). The two-way street integration model reflects a process that involves commitment on the part of newcomers to adapt to a new life in Canada as well as commitment on the part of Canadians to adapt to new people and cultures and to "ensure positive outcomes for everyone in the social, cultural, economic and 
political spheres"(Biles et al, 2008, 4). In other words, immigration triggers processes of integration on both sides: on the side of the host community as well as on the side of immigrants involving economic, social, cultural and political implications on both regional and local community levels (Galabuzi and Teelucksingh, 2010).

\section{The Host Program: What is known?}

It has been 25 years since the Host Program was created and, at this point, it is possible to see whether it has been effective in the settlement and integration of newcomers and in delivering the outcomes outlined above. There have been very few research studies targeted specifically to the Host Program, but those that exist provide clear evidence of the relevance and effectiveness of this settlement service.

Various sources of information on the Host Program have been unanimous in indicating that this program is appropriate and useful to newcomers in their integration and adaptation process (Evaluation of Host, 2004, George and Fuller-Thompson, 1997, Baldacchino et. al., 2009, Anisef, 2005, Kunz, 2005, Kerr and Powers, 2005, Consultation with Host Program Participants, 2008). According to an evaluation conducted by CIC through key informant interviews, focus groups and surveys, the Host Program is an important and significant service because it provides social support, expands social networks, improves the language and communication skills of newcomers and increases their access to public and community services. For example, most of the respondents reported that the Host Program provided them with important guidance in different aspects of life, including job searches, banking, shopping, etc. The majority of key informants indicated that participation in the program helped them to overcome initial stress and isolation and provided emotional support and friendship. Also, 
many focus group participants reported that, as a result of the Host Program activities, they improved their communication skills, expanded their social networks and increased their awareness of Canadian culture and values. Overall, the evaluation showed high levels of satisfaction with the Host Program among its participants (Evaluation of Host, 2004).

The importance of the Host Program is also identified by Kunz (2005) in her discussion paper which, through 3 volunteer-newcomer case studies, shows that the Host Program is indeed effective in developing networks outside of newcomers' ethnic community. She argues that settlement services like the Host Program facilitate better social and economic integration of newcomers through the development of social networks between newcomers and Canadian society. While acknowledging the importance of other settlement services (LINC and ISAP) she, however, urges not to underestimate the impact of the Host Program:

Being able to function and participate in any society requires an understanding of the rules and norms, both written and unwritten that direct people's behaviour. Cultural reciprocity, or the process of exchanging cultural cues and knowledge equally between hosts and newcomers, provides an additional important component of the foundation for integration. Many of these can not be learned in classrooms or from textbooks. Rather, they are acquired through informal communications (Kunz, 2005, 16).

Similarly, Kerr and Powers (2005) have stated that the Host model, including both group activities and individual matches plays an important role in building ties to the mainstream society. Although in their study examined group models the main objectives identified for group models were similar those of the individual match model: social network development and language practice. For example, in a research that studied the role of the Host Program in the retention of immigrants on Prince Edward Island (PEI) these exact same objectives were identified as the most important and crucial by immigrants who went through the Host 
Program's individual match model (Baldacchino et. al., 2009). Another important finding of their study of Host group models was that, although the group model is a promising and beneficial practice worth expanding and supporting, it cannot replace individual matches that promote strong, close ties between newcomers and volunteers when they interact on a oneon-one basis.

I strongly support this argument, ideally, any SPO that provides Host services should provide both group models and individual match models to their clients. Every client has unique needs and the service delivery model has to be tailored to those needs. Also, of course, the decision on which model should be used in each particular case has to be made in cooperation with the client. As Anisef $(2005,37)$ also notes: "group activities and individual matching would be mutually reinforcing, providing the most promising model for social networking and eventual bridging to the wider community". Moreover, some agencies expressed concerns in relation to the power dynamics that can emerge in group models where formal, classroom-like settings can make newcomers feel like "disempowered takers and volunteers as givers" (Kerr and Powers, 2005, 17). It is important to acknowledge that this kind of unequal relationship is also possible in individual matches where the host volunteer can serve as a 'surrogate parent' or 'patronising benefactor' (Baldacchino et. al., 2009). However, the likelihood of transition to a more equal type of relationship is very high as one immigrant who participated in the Host Program stated:

I started off on the unequal side with my match; but it quickly went on to the equal side and we became friends (Baldacchino et. al., 2009, 38). 
Baldacchino et. al's (2009) study specifically studied the Host Program in relation to immigrant retention in PEI. Through interviews, focus groups with newcomers and host volunteers, the authors also found that the Host Program is highly appreciated by immigrants for the opportunity it provides to improve English, build relationships with the broader community and adapt and integrate more easily. However, the research also found that it was ineffective in promoting retention of immigrants in PEI. The research showed that there is no direct connection between the Host Program and retention rates. However, the Host Program cannot be blamed for this, as PEI has specific integration challenges that undoubtedly affect retention. Islanders have very strong connection with networks of relatives and friends and some consider any immigrant as an outsider; immigrants are always 'come from away' and breaking into a 'tightly-knit' island community is almost impossible. This inability to fully integrate because of systemic discrimination in PEI society, coupled with the problem of finding suitable employment was found to be the main reasons for the poor retention rate of immigrants (Baldacchino et. al., 2009, 7).

As opposed to this, findings from another study indicate that the Host Program can actually be helpful in retaining immigrants in the receiving country (George and FullerThompson, 1997). Although George and Fuller-Thompson's study does not apply directly to the Host Program, it explains the issue of successful integration as a result of social networks. The authors looked at the characteristics that distinguish immigrants who plan to stay in Canada versus those who intend to leave. They found that immigrants with extensive and established social support networks are more likely to stay in the country and become established there. In this regard, the authors see the Host Program as an important tool of immigrant integration 
and suggest that it would be extremely beneficial if, upon arrival to Canada, every newcomer received Host Program services.

Anisef et al (2005) found that the Host Program and Host-like services are beneficial for new immigrants to the extent that it should be expanded to immigrant youth as well. He argues that a separate Youth Host Program with separate guidelines specifically tailored to youth would provide an effective response to the challenges faced by newcomer youth in helping them to adapt and integrate to Canada.

Along with its positive effects and benefits, the Host Program has problems and challenges, which I am going to discuss in the next section.

From the literature I reviewed I was able to identify a number of problems that either directly hinder the Host program from being used to its full potential or affecting it indirectly. These include a lack of promotion, lack of funding, and a disconnect between immigrant information gathering practices and the information providing practices of settlement agencies.

\section{Lack of promotion and lack of funding}

For this section, I draw primarily on the Host Program Conference working papers and summary reports for 2007, 2008 and 2009.

The Host Program Conference has been conducted on an annual basis since 2007; representatives of the agencies providing Host Programs in Ontario meet to learn about each others' programs. They identify and discuss issues and problems related to the program; its weaknesses and strengths, pressures and opportunities. One of the main themes that has been identified as a weakness and continues to emerge at every conference is the insufficient resources allocated to the program, which hinders its ability to be adequately promoted and 
advertised to the community (Ontario Host Program Conference, 2007, 2008, 2009). This exact same issue has been raised by the Host Program coordinators I interviewed for this study. Insufficient funding affects not only its ability to be delivered to more clients, but also hinders the opportunity for adequate promotion of the program in the community. From the conference reports and summaries I have reviewed promotion and advertising of the Host program is considered one of the major issues that needs to be addressed. One problem that was specifically singled out was the lack of media advertisement, lack of resources for promotion and lack of community-oriented campaigns (Ontario Host Program Conference, 2007). Recommendations issued from the 2009 Host conference to participant agencies also emphasized the need to promote the Host program more widely in the community (Host Conference Report, 2009).

Another key issue identified during conference focus groups and discussions is the difficulty of recruiting and then retaining volunteers within the program. However, as we will see later, the findings of this study will show a different situation with host volunteers and their recruitment. Since volunteers represent the main pool of resources for this project, it is natural to assume that special attention and emphasis would be put on methods of recruitment and establishing long term relationships with them. It has been agreed that agencies need to develop appropriate mechanisms to recruit and retain volunteers and develop 'effective methods of 'selling' the Host program to various audiences'. Agencies compete with each other for volunteers and this also indicates that there is a shortage of volunteers; a need which also has to be addressed (Host Conference Report, 2007, 2008, 2009). The reasons for this volunteer shortage may vary from complex to very simple, such as people just do not know about this 
program. It is quite obvious that people will be able to use or participate in this project only if they know about it. The executive summary of consultations with Host participants conducted by the Ontario Host Program Coordination Project in 2008 supports this evidence. Consultation findings indicate that 'It appears that many newcomers either don't know about the services' or 'can't access them'. Therefore, along with issues related to promotion of the program, issues of access appear to be no less important.

The disconnect between immigrant information gathering practices and information providing practices by settlement agencies.

One of the themes that emerged from the literature was the hypothesis that social exclusion issues could be provoked by a lack of information or lack of access to 'mainstream sources of information' (Caidi and Allard, 2005). Research conducted by Caidi and Allard (2005) for the CERIS project entitled "Social Inclusion of Newcomers to Canada: An Information Problem?" aimed to look at social inclusion theories from an informational perspective. They argue that 'information provision is a key component of social inclusion' (Caidi and Allard, 2005), and yet there is a lack of information about how new immigrants find and access information and if they have enough skills and familiarity in "utilizing various information institutions and related technologies' (Caidi and Allard, 2005). The authors draw on Chatman's theory of information poverty, which helps them to understand how different groups struggle to get useful information for solving everyday issues in life.

Chatman's theory is highly relevant and applicable to understanding and addressing the problem of underutilization of the Host program. She argues "that there exists a class of information poor - who lack access to information - and that is characterized by their difficulty 
or inability to obtain useful information either from people they know (insiders) or outsiders to their group or even from mainstream sources of information such as the media" (Chatman, 1985 as cited by Caidi and Allard, 2005). Thus, assessing the ways that define the "information practices of immigrants" particularly about settlement services and programs appears to be important in understanding why the Host program remains underutilized, even when its services are so necessary for new immigrants (Host Conference Report, 2007, 2008, 2009, George and Fuller-Thompson, 1997, Consultations with Host Participants, 2008). Therefore, "information (as a resource) and facilitating access to it should be recognized as necessary factors that enable inclusion of newcomers into adopting society" and "information providers and policy makers alike are urged to bridge the gap between social inclusion, social capital and the provision of information resources" (Caidi and Allard, 2005).

Thus, the literature suggests that the Host program is an undoubtedly successful settlement service that is worth expanding to a significant level. Also, better promotion and advertising of the Host program, both among new immigrants and the host society members, appears to be one of the main issues that needs to be addressed. This in turn relates to the lack of resources allocated for the program by the federal government. However, looking at these factors alone does not seem to be enough in addressing the challenges of the Host Program. Other important factors, such as the information practices of immigrants, need to be considered as well. 


\section{Chapter 4}

\section{Methodology}

The research question that guides this study is: Does the Host Program lead to better social inclusion of immigrants through expanding and enriching the social capital and social networks of newcomers?

\section{Approach}

Being a recent immigrant myself and coming to know about the Host program only during my study in this program, I became very interested in what this program embodies both for host volunteers and especially for newcomers, which I was until recently. The approach used in this study is qualitative, as, for me, this research started with acknowledging and situating myself within a particular social context. The qualitative method seeks to understand a given research problem or topic from the perspectives of the people it involves. It is especially effective in obtaining culturally specific information about the values, opinions, behaviours and social contexts of particular populations. The strength of qualitative research is its ability to provide descriptions of how people experience a given research issue. It provides information about the "human" side of an issue - that is, the often contradictory behaviours, beliefs, opinions, emotions and relationships of individuals. Qualitative methods are also effective in identifying intangible factors, such as social norms, socioeconomic status, gender roles, ethnicity, and religion (Neuman, 2006). However, findings from this study cannot be generalized to other newcomers; rather, they help us to better understand the ways in which 
the Host Program benefits both newcomers and host Canadians, and whether it eventually enhances the social inclusion of newcomers into host society.

\section{Sample and Recruitment}

Qualitative research uses small samples that are selected based on particular criteria (Ritchi and Lewis, 2003). The original sample of this study consists of six respondents from three different groups of people related to the Host Program. These categories include: SPO staff members who are directly responsible for the delivery of the Host Program, Canadian volunteers who delivered or are in the process of the delivery of Host services to newcomers, and newcomers, who have received or are in the process of receiving Host Program services. Two respondents from each category have been interviewed.

All respondents had to meet the following criteria:

- Above the age of 18

- Able to communicate in English at the time of the interview

As the main objective of the study is to seek information about the respondent's feeling of social inclusion after or during receiving the Host Program services, information has been collected on a range of topics related to social networks, friendship and integration.

SPO staff participants were recruited through my (the researcher's) circle of professional contacts, which I developed as an Immigration and Settlement Studies student at Ryerson University and my place of internship. Newcomer and host Canadian participants were recruited through the SPO staff. The staff members have been given recruitment materials and disseminated them among their clients. As a result, two newcomers and two Canadian residents acting as a host contacted me and expressed a desire to participate in this study. 


\section{Data collection}

Individual in-depth interviews were conducted with participants in the study. Each interview took between 40 to 60 minutes and was guided by a list of prepared questions (see Appendix 3). The interviews were conducted at a mutually convenient time and place. As all the respondents are proficient in English, the interviews were conducted in English. Also, the consent form and recruitment materials were provided in English (the consent form and recruitment material script are available in Appendix 1 and 2). All the interviews were tape recorded and then fully transcribed. This method gave me different points of view on the issues and challenges existing in the Host Program from the most interested, the most involved and the most affected.

\section{Researcher's position}

While conducting the research I am fully aware of my own position. As a relatively recent immigrant who would have enormously benefited from the Host Program, I was deeply interested in learning about the opportunities provided by the Host Program from various perspectives. Also, being an immigrant myself, I shared a number of similarities with newcomer participants, which allowed me to establish a rapport with them. Moreover, knowing about our commonalities allowed them to feel more relaxed and share details they may have hesitated to share with another researcher.

\section{Limitations of the study}

Any research has its shortcomings and this study is no exception. There are two major limitations of the study. First, the sample of six is small and does not enable the findings to be generalized to all newcomers who went through the Host Program and all Canadians who volunteered as a host. Incorporating a greater number of participants in the study may have 
provided data with richer and more varied perspectives to the data. Second, it does not involve the government sector's perspective on the subject, which deprives the study of insights on issues of funding and promotion from the funders' perspective. Getting consent to interview government official involves a complicated and lengthy process of acquiring permission from the Communications branch of $\mathrm{ClC}$. Unfortunately, the timeframe limits of this study did not allow for enough time to get this permission. Hence, I acknowledge that this research lacks the funder's perspective on the future development and enhancement of the Host Program.

For the purposes of confidentiality, in the following section, research participants will be referred to by numbers based on the sequence of their interviews i.e. Host Coordinator 1, 2; Volunteer 1, 2; Newcomer 1, 2. 


\section{Chapter 5}

\section{Research Findings, Discussion and Conclusion}

In this chapter, I will discuss the main findings of my research regarding the Host program and its influence on the lives of newcomers and Canadian society in general. The following important issues that will be highlighted are:

- The effectiveness of this program in the adaptation and integration of newcomers from the perspective of the SPO staff;

- impact of the Host Program on the adaptation and integration of newcomers in Canada from the perspective of newcomers;

- benefits of the program for Canadians from the perspective of volunteers;

- issues related to promotion and funding

Each of the topics will be examined below with illustrations from the data. The chapter ends with a discussion of the findings in combination with existing literature and general conclusions.

\section{Effectiveness of the Host Program in the Adaptation and Integration of Newcomers}

This section provides a SPO staff perspective on the effectiveness of the program. The views of other respondents are provided below in other sections of the findings. Interviews were conducted with two Host coordinators working in different SPOs that provide the Host Program services to newcomers. Both Host coordinators, independent of each other, identified almost the same benefits and characteristics that distinguish the Host program from other settlement programs and what makes it effective in the integration and adaptation of new 
immigrants. They came to the conclusion that the most unique characteristic of this program is

the way the service is actually provided. As both Host Coordinator participants emphasized:

In some cases they are [newcomers] too hesitant to go book an appointment with a settlement counsellor [...] in our site it is a drop in feeling. They can come and feel safe in some cases and through us, we then help them build confidence to access all the other services or understand all the services that available to them (Host coordinator 1).

In other programs, you are dealing with settlement workers; however, in the Host Program it is friendship-based. So many people are reluctant to go seek help from professionals or counsellors, or social workers; however, when it is from a friend they are more comfortable and more at ease. [...]They think the person [settlement worker] have them because they have to, it's their job. But with a volunteer who is matched with them they do it because they care about them, not because they have to (Host Coordinator 2).

Host Coordinator 2 emphasizes this point further, stating that the Host Program is a program that actually addresses human needs; that is to "have someone that you belong to and you care about". In this case, the program seems to address the human needs of both volunteers who want to take care of newcomers and newcomers who want to feel included in and want to belong to the host society.

When people immigrate to a new country they leave so many things behind, including family members, relatives and friends. Being an immigrant himself, Host Coordinator 2 shared how important it was for him to have a friend in his new country:

When I came to Canada in 1980 I had a place to live, I had a job, but I had no friends. So for me it was very traumatic experience to be away from the family and friends. If when I came to Canada, I had even one friend on top of what I already had, I would have been happiest man in the world.

Making friends, connections and building ties to the broader community has also been identified as a very important feature of this program. Both respondents discussed the role of the Host Program in connecting people and building networks. They support the argument that 
the Host program helps newcomers to make friends, which reaffirms one of the main objectives of the program:

Another huge area is making friends. A lot of them [clients] will come either through family sponsorship or as GARs [government assisted refugees] and they tend to not have a huge networks, so this is the place for them to build that network (Host Coordinator 1)

Throughout the past year, we've seen a group of strangers come together to now building what I think is life-long friendships (Host Coordinator 1 ).

When asked the question about the main positive effects of the Host Program, Host

Coordinator 1 identified connecting people to a mainstream community as the most important:

Connecting people, getting connected to people in your community.

Host Coordinator 2 thinks that the main positive effect of the program is:

To settle in healthy way, to get to know the services and to participate in community events (sic).

The above comment illustrates the role the Host Program plays in the integration and adaptation of newcomers from service providers' perspective. It outlines the importance of the way Host Program services are provided; it also emphasizes its ability to connect people and build friendships. The next section will show what newcomers themselves think about the Host Program and its role in their life. It will be interesting to see and compare to what extent service providers know and understand the impact of the program on their clients.

\section{Impact of the Host Program on Newcomers}

In this section, I draw primarily on the data collected from newcomer respondents; however, in order to highlight some of the points made by newcomers, SPO staff's and volunteer's perspectives will also be incorporated. Newcomer 1 has been in a friendly 
relationship with her volunteer for three months, but now, due to a mismatch in their schedules (the Volunteer can meet on weekends only, and Newcomer 1 is busy on weekends with family errands) she is waiting to be matched with another volunteer. As of the time of the interview Newcomer 2 has been in a relationship with her volunteer for six months.

Overall, both newcomer respondents reported very positive experiences with the Host Program. The feeling of confidence and comfort that their interactions with volunteers gave them was the first point they brought up when asked about the positive impact of the program:

When I came [to Canada] I had many problems. Too much thinking about everything, everything was new. But after I came to Host Program everything changed. I feel comfortable now. Before I was shy, I couldn't speak in front of people but now I can. [...] Because of my volunteer now I speak and feel more confident (sic) (Newcomer 2).

Before [coming to the Host Program] I was scared to talk, but now I am comfortable, I can talk with anyone (sic) (Newcomer 1).

The issue of comfort seems to be quite significant in the whole newcomer-host interaction process. One of the interviewed volunteers also emphasized the importance of making newcomers feel comfortable in order to have successful interaction.

You make them [newcomers] laugh because you don't want them to sit and feel uncomfortable, because then you are not really helping. And when they feel comfortable they learn much faster, when they get comfortable they can ask you how to say this and that, what does that mean, etc. (sic) (Volunteer 1).

During the interviews, volunteers were regarded by newcomers as friends many times.

Both newcomers seem to have a very warm and close relationship with their host volunteers.

This corroborates the assumption of Host Coordinators that this is a friendship-based program.

For example, as already mentioned above, despite termination of their host-newcomer relationship due to discrepancies in the schedule, Newcomer 1's former host match still keeps in touch with her and their relationship has moved into the category of friendship: 
She still calls me and we talk. She is not like my volunteer, she is friend, like, close friend. She came to my home for dinner. I can call her and ask her for advice. For example, I wanted to learn about driving and she helped with that (sic) (Newcomer 1).

Similarly, Newcomer 2 also sees her host as a close friend and even considers her part of her family:

Once she invited me for lunch with my kids to her house. We cooked the dinner together, we made pizza, and we watched movie for kids. My kids were so happy! I feel like we are family [...] Even she told me that if I need go somewhere she can sit with my children. Yeah, she is very nice. She is like my sister now (sic) (Newcomer 2).

There is a wide range of activities that volunteers do together with newcomers. These activities provide tangible assistance in navigating the realities of life in a new country. Every newcomer has unique needs and it seems that these needs are being effectively addressed through individual match relations:

Sometimes, when you have a problem, they [volunteers] give you advice, then we go out to library, learn how to use computer. Sometimes, we do some activities outside [...] we went to the park and saw refugee camp exhibition. If my children need something, our volunteer helps us to find it, explain how to use it. If I need to go somewhere I call her and we go together. [...] When I wanted to change my name, she gave me advice how to do it better. When I wanted to buy computer she helped me to choose cheaper one and explained everything (sic) (Newcomer 2).

[...] because they give us volunteer who help us with everything. They sit with us and they talk with us, and we can improve our English and we learn many things. She teach me how to use computer [...] how to use bus, how to go, about direction. Whenever I need to know about, like school, she tells me about it. She teaches me how to adapt to Canadian culture (sic) (Newcomer 1).

When SPOS describe the Host Program on their websites or advertisement flyers, learning about Canadian culture is depicted as an important part of the program. However, I have heard very little about this aspect of the Host Program from my newcomer respondents, as they seem to value more tangible and directly applicable aspects of the program, such as making friends, learning conversational English, learning how to use computers, etc. As opposed to newcomers, 
volunteer respondents elaborated on this issue and explained what kind of cultural adaptation immigrants need to go through in order to become better integrated into Canadian society. At the same time, the following comments show that Canadians have certain perceptions and stereotypes about immigrants that affect what they think should be addressed through settlement services like the Host Program:

There is certain way, like Western, Canadian, that we expect certain things, certain amount of politeness. You expected to be courteous to anyone, so they are learning all that. They are learning what you can and cannot do. There are the rules that they have to follow basically (sic) (Volunteer 1).

When asked what kind of rules she is talking about, Volunteer 1 explained:

For instance - spanking in the public - that is a no no here. So they have to learn that. They have to be polite to others - it's not acceptable to spit wherever they want (sic).

Volunteer 2 also thinks that learning how to do things in the 'Canadian way' helps newcomers

to build networks with their host society:

Once you establish good comfort level, newcomers are more open to ask questions about if it is right to do this and that, you know, questions about doing things in Canada. Whether it's accepted or not. This helps them a lot to get along in the new country and find their ways (sic).

At the same time, Volunteer 1 acknowledges the importance of retaining the newcomers' own identity and sees it as one of the integration challenges that immigrants face:

Finding out what means to be Canadian, try to understand how to integrate, how to not lose yourself and still be Canadian. And it is kind of hard. You don't have to lose who you are to become Canadian (sic).

Another important impact that the Host Program has on newcomers involves language proficiency. Being one of the most important dimensions of life in Canada, it seems that participating in both individual match and group activities improves the language proficiency of newcomers considerably. 
I like the program. Conversation circles are very good; they help to understand different people and different accents (Newcomer 1).

English conversation class helped a lot to learn English and to start speaking. [...] First time when I met her [volunteer] she told me - "Don't be shy and repeat your questions many times if you need. If you don't know the word, ask and I repeat it. Don't worry I will try to understand you." Now when she speaks I understand everything, even on the phone. [...] Also, before, when I go to places like banks, stores, telephone companies I looked for people who speak Arabic, now, since I am in the Host Program even I see that teller speaks Arabic I don't go to her, I go to English speaking teller (sic) (Newcomer 2).

The LINC offered by the Canadian government is specifically geared to learning languages.

However, it seems that the Host Program makes contributions to different areas of language proficiency, which are, perhaps, not covered by LINC. One of the volunteers has her own important point on what particular kind of language usage it helps immigrants to learn:

Most of the English is slang and I tell them - you have to learn the slang. [...] For example, there are number of different ways to say washroom and they need to know this, that there is not just one way to say things. Or things like dude, it's very Canadian, like - hey dude! They need to know it (sic) (Volunteer 1).

The issue of slang was also emphasized by one of the Host Coordinators. She admits that

knowing slang can help newcomers to be better connected to mainstream society:

Ninety percent of our clients attend LINC but they don't have a place to go and practice conversational English and the place to pick up on slang. Because a lot of conversing in the neighbourhood or getting to know other people is the slang piece. So that's a huge area (sic) (Host Coordinator 1).

The available data also supports the hypothesis that was put forward in this study that the Host

Program helps to expand the networks of newcomers and to build ties to the broader

community. Both newcomers responded positively to the question of whether volunteers help introduce them to their friends:

She wanted me to meet her friends. She took me to her friends' house, they had get together party, we cooked little bit, then we ate it, and we had fun (sic) (Newcomer 1). 
Once we went to the ROM [Royal Ontario Museum] and she came with her boyfriend. I was with my daughter, so we met her friend and we talked (Newcomer 2).

I also asked my volunteer respondents the same question and both of them have a positive attitude towards introducing their newcomer match to their friends. Volunteer 1 has introduced her match to her mother, and she mentioned that, if the occasion comes up, she will definitely introduce her match to her circle of friends as well. Volunteer 2 had already introduced her newcomer match to her friends when she invited her and her family over for dinner. Both volunteers regarded introducing their match to their friends as a natural part of their relationships with the newcomers.

Based on the above research findings, it seems that the Host Program plays a significant role in newcomers' integration and the adaptation process by providing a sense of confidence and comfort and by assisting in exploring and understanding the Canadian lifestyle. More importantly, this assistance is provided in an informal, friendly manner by volunteers that are seen as friends rather than professional settlement workers. This allows newcomers to feel more comfortable when seeking help, i.e. ask more questions and discuss problems and issues more openly. Data also shows that the Host Program considerably improves the conversation skills of newcomers by allowing them to practice their skills with a native speaker as well as other immigrants from different ethnic backgrounds. Most importantly, it allows them to learn more conversational language with elements of slang inherent in Canadian speech, which helps in their interactions with their Canadian counterparts. Lastly, respondents emphasized the importance of the Host Program in building networks and ties to the mainstream community through the friends and family members of host volunteers. 
Impact of the Host Program on Volunteers

As already mentioned above, following the assumption that the integration of newcomers is a two-way process, it is very important to understand and discuss the impact that the Host Program has on its host volunteers. Although I will provide not only volunteers' perspectives on this issue in this section, how they (volunteers) see it appears to be particularly important in understanding what this program can bring to the members of the receiving society.

From the very beginning of this research, I was deeply interested to know what motivates Canadians offer their time, knowledge and friendly assistance to newcomers. Through interviews with my volunteer respondents I have been able to shed light on this issue. Volunteer 1 is doing this for the first time, whereas Volunteer 2 has been offering a helping hand to newcomers for almost 6 years. Both of them are Canadian-born residents of the local communities. Each of them has their own valuable experiences and perspectives to share.

Volunteer 1 admitted that at first she was attracted to this program for the valuable work experience she would be able to use to further her professional career. In fact, both volunteers see the immigration and integration field as a future career path for themselves.

I was looking for internship; I just finished the school and wanted to get work experience (Volunteer 1 ).

The second motivation for coming to the program for Volunteer 1 was the idea of working with and helping immigrants:

I also really like [working] with newcomers and immigrants, I like the whole idea [of the Host Program]. 
Volunteer 2's decision to participate in the Host Program stemmed from a different reason.

Having experienced living abroad herself, she knew very well what immigrants go through upon arrival in a new country:

Because it is a very rewarding experience for me to know that I am helping someone to adjust to life and culture in new country. I have experience travelling and living abroad so I know how difficult it can be to resettle or adjust to the new culture, so if I can make it easier for people coming here, I would like to help.

However, she also considered participation in the program as a valuable experience for future job searches:

[Volunteer work] could also be beneficial for getting experience for resume purposes. In addition, Host Coordinator 1 has noted that being an immigrant is also a strong motivation to become a volunteer, as former immigrants have a very clear understanding of how this kind of service can help newcomers during the initial stages of settlement:

We've had a lots of people come out and say - you know, I was an immigrant, or my parents were immigrants and this service didn't exist, it would have been so helpful (Host Coordinator 1).

It was interesting to compare answers that volunteers and immigrants provided to the question about activities they do together. From the answers provided by volunteers it seems that the Host Program covers quite a wide range of newcomers' needs in the initial settlement process. The variety of activities that volunteers named exceeds the list of activities that newcomers have named in the previous section:

We go to lots of festivals. When she [newcomer] has to speak to someone, like customer service at Rogers, Fido, I just go with her and help her. [...] or if she needs to fill the forms and if she doesn't understand when someone speaks fast I also help her. We go to grocery stores, and sometimes, we just talk on the phone (sic) (Volunteer 1). 
Sometimes we sit and have coffee, because they want to practice their conversation English, so we talk about their family, their country, about life in Canada. Sometimes I help them with their ESL homework. We go swimming together, we cook together (Volunteer 2).

As a natural consequence of the type of activities and length of time spent together, volunteers, just like newcomers, often refer to their newcomer matches as friends, rather than someone they just help. Moreover, they admitted that they themselves learn a lot from their newcomer matches:

We have good conversations now; she is becoming a good friend. [...] I am learning from her. I am getting to learn Spanish, I am getting to learn about her culture (sic) (Volunteer 1).

I feel quite close to this family, very attached. [...] And also it is an opportunity for me to learn about other cultures; it is quite beneficial to meet new people, form new friendships and relationships (Volunteer 2).

In accordance with what volunteers think is beneficial for them in this program, both Host

Coordinators also outlined a number of points:

For volunteers - getting to know about the culture of the person. Some people have stereotypes about immigrants, their culture, religion, so for them to meet someone from certain cultural religious background is very beneficial to overcome those stereotypes. So it is very educational, eye opener, very enriching to the soul. You don't have to travel the world, you just meet the world right here (sic) (Host Coordinator 2).

It is very 'feel-good' thing when things go well. People are helping people. The volunteers are gaining so much - they are learning about other cultures, they are gaining experience, they are being able to see things through another person's perspective (Host Coordinator 1).

Volunteer 1 confirmed the Host Coordinator 1's last statement, saying that:

Every time I meet with my family I just feel so good, my mood lifts! It is so rewarding. It is funny that it doesn't even feels like a volunteer job, it is more like a hanging out with friends. It is fun (sic). 
Overall, from my conversations with both Volunteers I got the strong feeling that they enjoy their time spent with newcomers and appreciate all the benefits they get from their relationships with newcomers.

Both volunteers also demonstrated a good knowledge of the integration and adaptation challenges that newcomers face upon arrival to Canada. They seem to understand the importance of being connected to mainstream society, which can help to avoid isolation and ethno-racial segregation. They truly believe that this program enables newcomers to move outside of their own communities and build networks which connect them with mainstream society and other immigrant groups:

[...] generally, you know, you tend to speak with your own community. It is (Host Program) really great in that it helps to meet different people of different ethnicity. This is very important, especially in Canada. They [newcomers] learn about Canadian culture, they meet people from everywhere, they get to mix, so they are not isolated (sic) (Host Volunteer 1$)$.

I think that a lot of immigrants tend to stick with people from their home country. It's easy to stay with their own people. But getting immigrants out to the community, getting them to interact with other people, either Canadians or people from other countries is really beneficial to them. And then it helps them to create networks of all kinds which might help them if they have difficulties finding jobs or even just with the language (sic) (Host Volunteer 2).

The element of the Host Program that enables newcomers to meet different people from different ethnicities is the group activities that are being increasingly offered by the Host Program providers. In addition, this part of the Host Program seems to play significant role in orienting newcomers to life in Canada. Being free of charge for newcomers, it enables them to meet in groups with newcomers from different countries and learn things from both each other and from a facilitator from the local community, go on field trips to museums and other sights of their host city and country, such as the Royal Ontario Museum and Niagara Falls: 
The Host Program also organizes different activities for them [newcomers], and most importantly, they reimburse the fees, because many newcomers face financial problems when they arrive, so it really helps them to get out and see and learn things (Volunteer 2).

Group activities also seem to be a very important part of the Host Program for newcomers as a source of friends and networks. As both newcomer respondents shared:

I learned about Canada, things like pot luck, about how to meet people. I also learned more about different cultures and religions because of this program. And I made many new friends here. Now I have a big circle of friends. I am alone here just with my husband so whenever I feel lonely I call my friends and talk with them. Sometimes we go out together (sic) (Newcomer 1).

For example, classmates from conversation circle are my friends now. We went several times to different places, took pictures together. We call each other and go for walks (sic) (Newcomer 2).

From the data outlined above we can see that things such as getting professional experience, helping others and having empathy and an understanding of the difficulties of integration impel people from the receiving society to become host volunteers and offer their time, help and friendship to newcomers. It also demonstrates that integration can really be a two-way street type of process and Canadians can gain as much immigrants from their mutual relationships. It shows both volunteers' perspective and the Host Coordinators' perspectives on the impact of this program on Canadian volunteers and how it is capable of changing the stereotypes and perceptions of the receiving society towards new immigrants. The data also shows that volunteers have certain assumptions about what it means to be Canadian and about the kind of rules that newcomers need to learn in order to become Canadian. At the same time, volunteers acknowledge newcomers' right to retain their own identity and are well aware of the integration issues and challenges that newcomers face. 
Despite all the benefits and potential of the Host Program shown in the previous sections, the following section reveals some of the issues that need to be addressed in order to enhance the effectiveness of the program. The data below will show the problems of the Host Program as seen by immediate participants.

\section{Funding and promotion}

From the answers of the participants, I have been able to identify two major issues inherent in the Host Program that hinder its success and effectiveness. The research findings turned out to be consistent with the problems previously identified in the literature review, which are funding and promotion.

All participants were asked questions about what they think are the biggest challenges and problems of the Host Program. Both Host Coordinators mentioned the issue of insufficient funding first. Funding seems to be a major problem because all other problems are closely tied to the budget that is available to service providers. The extent and scope of promotion, recruitment of more clients and volunteers, better coordination between SPOs providing the Host Program and training and workshops for the Host Program staff all require funds and funding. The amount of funding that is allocated to the Host Program doesn't seem adequate to cover the activities listed above and increased funding would considerably improve the delivery of the program:

The Host programs in Toronto - there is lots of room to grow. There need to be more funding, more staffing, more coordination (Host Volunteer 1). We've actually looked at Toronto Star, we've looked at the radio station, and everything is a little bit out of our budget range. For subways, there was actually discussion about all the Host Program in Toronto to do a TTC initiative, but the funding wasn't there (sic) (Host Volunteer 1). 
Ads on TV and radio are extremely expensive. [...] The funding for promotion is not enough and we try to do it in more traditional way. We have free ads in local newspapers; we have our flyers available at the library and other agencies (Host Coordinator 2).

Promotion is crucial in ensuring that newcomers know about the existing service as, according to the data, SPOs have the capacity to serve more clients than they currently do. As Host Coordinator 1 stated:

Demand-wise, we definitely have space for a lot more clients.

However, as she continues:

Not a lot of newcomers actually access the Host Program because it is not known that it exists.

Interestingly, both Host Coordinators indicated that they do not have a shortage of volunteers; in fact, they had more volunteers than newcomers:

At the moment we actually have a surplus of volunteers (Host coordinator 1). We don't have a waitlist because we have enough volunteers. When we started, the challenge was to find the newcomers (Host Volunteer 2).

Data indicates that SPOs use almost the same methods of promotion of the program among both newcomers and volunteers. These methods include online postings, flyers, advertisements in local community newspapers and networking of SPO staff with local community members. However, it seems that this scheme works better to recruit volunteers. Suggestions on how to promote the Host Program to attract more newcomers have been made by volunteer respondents:

They probably have to try TV or radio I think. TTC is also good one, because a lot of people are going to see it (Volunteer 1).

Advertisement campaigns in newspaper and television; and sort of promote how it changes newcomer's lives and what Canadians gain from newcomers (sic) (Volunteer 2). 
The data shows that SPOs do not have enough funding and therefore cannot advertise their services on mainstream media sources, such as TV, radio and in places of large concentrations of immigrants, such as the $\pi \mathrm{C}$ system.

The extent and visibility of the current promotion of the Host Program can be seen from the responses that newcomer and volunteer participants provided when asked how they learned about this program. Both newcomer respondents learned about the Host Program during their LINC classes after the Host Program staff visited them in order to attract clients. Also, neither of the Volunteer respondents learned about the program from advertisements. Volunteer 1 specifically looked for the program on the internet, as she was looking for an internship opportunity. Volunteer 2 heard about the program from her friend and former classmate who was working as a Host program coordinator. All of my respondents could not recall seeing advertisements for the program outside on the streets, on the media or on the TTC system. For instance, Volunteer 2 frankly stated:

I have never seen openly ad solely on the Host program.

These findings show that promotion is a significant issue to bring program to its full capacity. This, in turn, requires adequate funding, which is needed not only for promotion, but also for issues like professional development and the coordination of SPOs that provide Host services.

\section{Discussion}

This research project set out to explore the role, if any, of the Host Program in establishing networks and ties between newcomers and host society members, and whether this leads to the better social inclusion of newcomers in the receiving society. 
From the responses of six participants, four of whom are direct beneficiaries of the Host

Program i.e. newcomers and volunteers, it is evident that participation in the program has undeniable benefits for both sides. For Canadians, these benefits include learning about other cultures, better understanding of the needs and challenges of newcomers, overcoming prejudices and stereotypes about other religions, traditions and customs which, in turn, promotes social cohesion. Another important thing that volunteers gain from their interactions with newcomers is a valuable experience which can help them in their future careers. In turn, newcomers also benefit enormously from participating in the Host Program. Regular contacts help them to considerably improve their conversational language skills, including the use of slang, which has been noted by the Canadian participants to play an important role in everyday interactions with friends and neighbours from mainstream society.

Moving to a new country is always accompanied by enormous stress and culture shock (CIC, 2004) and, therefore, having someone to help during the transition period is highly valuable. The data demonstrated that this is exactly what volunteers do: newcomers get important help and guidance in navigating the realities of Canadian life - such as grocery shopping, banking, gaining an understanding of the transportation system, and becoming familiar with an integral part of life in Canada - computers. Without help from someone who lives in this country and is familiar with all the nuances of life in Canada, each of these tasks would have been much more challenging for newcomers. Also, something that previous studies have not discussed is another important characteristic of the Host Program - the sense of confidence and comfort that this program brings to its newcomer participants. I believe that this is another important characteristic that distinguishes the Host Program from all other 
settlement services. Above, newcomer respondents described feeling more comfortable and confident in their everyday interactions with members of the mainstream community since entering the Host Program. If newcomers, as a result of regular informal interactions with host volunteers, feel more comfortable and confident in their relationships with other members of mainstream society, one can rightly say that these newcomers are on their way to becoming full members of society. Moreover, I think that being comfortable and confident in interactions, not only with one's own community members, but also with members of the mainstream community, means that these newcomers have a greater potential to fully contribute to all aspects of life in their new country in the future.

As to the most important part of answering the research question positioned in this study regarding building networks and ties to the broader community through the Host Program - research findings suggest that immigrants who receive the Host program services do form networks and friendships with the members of the mainstream community. First of all, as evident from the research findings newcomers form quite warm and close relationships with their volunteers. This confirms the findings of the 2003 survey conducted for $\mathrm{ClC}$ to evaluate the effectiveness of the Host Program, which demonstrated that $97 \%$ of newcomers considered their hosts as friend (Power Analysis Inc., 2003 cited in Kunz, 2005). Indeed, as is evident in this study, the volunteers themselves become an important part of newcomers' networks and the ties they form outside of their ethnic communities. These kinds of ties contribute to the previously discussed bridging networks and they determine the extent of the immigrant's success in a new country (Kunz, 2005, Beugelsdijk and Smulders, 2003). 
As already mentioned above, bridging ties enable individuals to access resources that are otherwise not available to them. For example, in the case of the Host Program, these resources include - being introduced to the family and friends of one's host volunteer, being invited to the volunteer's home or the home of volunteer's friend. As we can see from the findings, both newcomers have been introduced to the friends and family members of their volunteers, and one of them was invited to a party. Of course, this does not mean that newcomers immediately form friendships with their volunteers' friends and family members. However, compared to newcomers who are not in the Host program, and who, most likely, do not have even the opportunity to be introduced to people and invited to the house of someone who is not from their own ethnic community, these kinds of relationships undoubtedly enrich newcomers' experiences of interactions with people from mainstream communities. In the case of newcomer-volunteer relationships, the most important thing is to see whether they keep in touch after completing the required time in the program (Kunz, 2005). The findings of this study suggest that they are most likely going to keep in touch; both volunteer respondents stated answering the question of whether they are going to keep in touch with their newcomer match:

Yes, of course! Our relationship is turning to a great friendship. I think it will be kind of mean of me if I just stop calling. Yes, I think we will keep in touch (Volunteer 1).

If I would predict my relationship with the present family I am working with, without a doubt I definitely know that I will keep in touch, even if I move away (Volunteer 2). According to these findings, there is usually a good chance that volunteers will maintain relationships with their newcomer match for a longer period of time than required by the program and will be an important part of newcomers' networks with mainstream society. 
The problems and challenges identified by current research confirm those found in the literature. A lack of funding does seem to be a major issue that hinders the effectiveness of the Host Program. First of all, as research has demonstrated, it affects the capacity to promote the program in the most effective way, as suggested by the participants of this study. These include: TV, radio, transit systems, and I would personally add, places with a large concentration of immigrants, such as grocery stores, reception areas of family doctors, hospitals and government institutions where newcomers get their health cards, SIN numbers, etc. These methods of promotion, especially through mainstream TV, radio and the transit system have been reported by the Host Coordinator participants as extremely expensive and not affordable considering the budget of the program. Competition between SPOs for clients has also been brought up by one of the Host Coordinators as an important issue that hinders increased awareness about the Host Program among newcomers. This situation has been created by the current funding system that makes SPOS enter into unhealthy competition for clients. For example one of the Host Coordinators complained that when she tried to promote the Host Program through the other settlement agencies in the area that do not have Host services. Unfortunately, her suggestion had not been met with enthusiasm and she was not allowed to come and tell about the Host Program to LINC clients of that agency. She assumed that they feared to lose their clients and this seems to be a huge issue in the whole settlement sector today. Detailed discussion of this issue goes beyond the topic of current study; however, in relation to the Host Program if funder will require promotion of Host services among LINC clients of every SPO that is funded to provide language services this may help to considerably increase awareness about the Host Program among newcomers . 
The current means of promotion that are available to the SPOs are inexpensive and affordable methods, such as free postings in the community newspapers and on the internet, and the dissemination of flyers in local libraries and other agencies. While being effective in attracting host volunteers, these promotion methods seem to be ineffective in terms of attracting enough newcomers. Also, these findings probably point to the same direction as a research conducted by Caidi and Allard (2005) which stated that newcomers may not be able to access the information they need in the same way as members of the mainstream community. They suggest that immigrants may not have the skills or familiarity in utilizing information technologies such as computers and the internet. I think this may be especially true for certain categories of immigrants, such as government assisted refugees (GARs) or those who came through family sponsorship. These, however, are the newcomers that are the most in need of services such as the Host Program.

Given that both newcomer respondents emphasized the importance of teaching computer skills to their volunteers, they would have never been able to find out about the program from the internet postings that many agencies use in their promotion practices. Another important barrier is poor language proficiency, which may prevent newcomers from learning about the program from flyers, newspapers, online postings, etc. In this case, the word of mouth method and personal networking with local ethnic communities used by our Host Coordinators respondents seems to be one of the most effective means of reaching newcomers.

Newcomers tell newcomers. Like the word of mouth - if you provide good services it will bring more clients. Every newcomer is attracted to another newcomer, because they have similar problems, needs, and speak one language. The other thing is building 
good relationship with the community, for example churches, mosques, temples, community organizations (sic) (Host Coordinator 2).

According to the findings, more funding is also needed for the professional development of Host Program staff to increase their number, to improve the delivery of the program and, to be able to rent more space to conduct more group activities. Unlike in the literature review, the recruitment of volunteers did not prove to be a problem, as both Host Coordinators said that they have a surplus of volunteers. However, we must remember that the findings of this study cannot be generalized to the all Host Programs and its participants due to the small sample size used. These findings can only point towards some trends and existing issues that can be taken into consideration and explored in future studies.

\section{Conclusion}

I have argued that the Host Program may lead to the better social inclusion of newcomers in host society through the formation of networks and ties with the mainstream community. Overall, when examining the social inclusion and social networks of newcomers in relation to the Host Program, it seems that it does facilitate the formation of networks with the mainstream community. As the research has demonstrated, the volunteers themselves become an important part of newcomers' networks with Canadian society and help them to effectively navigate through the most challenging part of the settlement process - the initial adaptation period. Moreover, as this study has demonstrated, interactions with host volunteers gave newcomer respondents a feeling of comfort and confidence which in turn enabled them to feel more at ease in their interactions with other members of the mainstream society. This is very important, as being able to freely interact with members of the host society enables 
newcomers to access and benefit from more existing services, make friends outside of their own communities and eventually may lead to more successful integration and inclusion in the receiving society.

This is reinforced by development of language proficiency skills by participation in the Host Program, particularly through conversation and the use of slang. The benefits that host volunteers gain from this program may also have a positive impact on the social inclusion of newcomers, as learning about other cultures, religions and customs facilitates better acceptance and tolerance towards new immigrants on the side of Canadians. It also helps to overcome the stereotypes and prejudices that many Canadians may have concerning newcomers and positively change their overall perception of immigrants. If we remember that social inclusion means full and active participation in all aspects of life of the host society (Robinson, 2000; Sen, 2001 cited in Omidvar and Richmond, 2005) it is likely that newcomers who benefit from Host Program services will be more socially included and integrated than those who did not. To be able to firmly answer this question, an experimental and extensive research, comparing newcomers who participated in the Host Program with those who did not, needs to be conducted. 


\section{Appendix 1}

\section{Recruitment Script}

\section{Research Project - The Host Program and Social Inclusion}

Researcher: Zebiniso (Nisa) Abduvaitova

Academic Supervisor: Myer Siemiatycki

Program: Immigration and Settlement Studies (MA)

Institution: Ryerson University

I am conducting a study to develop better understanding of the role of the Host Program and its contribution to social inclusion of newcomers into host society. This research will also serve as an external evaluation of the Host Program's effectiveness and relevance to the needs of new immigrants.

I would like to invite you to take part in an interview, lasting approximately 60 minutes. You will be asked to answer a list of interview questions that are related to your experiences with Host Program and receiving Host Program services. Interview will be scheduled to take place in a private and quiet setting chosen in agreement with you. Some possible areas to conduct the interview would be a private study room in your local public library, community centre, graduate study room at Ryerson University or any other place that you would choose. The interview would be tape recorded; however, you could request that the tape be turned off at any time. All of the interview data will be kept strictly confidential in a place where only I will have access to. Also, your participation in the interview is completely voluntary and you may exit the study at any time.

Please email me at zabduvai@rverson.ca if you would be willing to participate or if you have any questions about the study.

Thank you,

Zebiniso (Nisa) Abduvaitova 
Appendix 2

\section{Consent Form}

Ryerson University

MA Program in Immigration and Settlement Studies

350 Victoria Street, Toronto Ontario

Canada M5B 2K3

Telephone (416) 979-5500 / Fax (905) 979-5341

\section{Title:}

\section{Host Program and Social Inclusion}

\section{Investigators:}

The name of the researcher in this study is Zebiniso (Nisa) Abduvaitova. The research is in partial fulfilment of the requirements for Ryerson University's MA program in Immigration and Settlement Studies. The supervisor of Zebiniso (Nisa) Abduvaitova is Professor Myer Siemiatycki.

\section{Purpose of the Study:}

This research project aimed to develop critical understanding of the role of the Host Program and its contribution to social inclusion of newcomers into host society. This research will also serve as external evaluation of the Host Program's effectiveness and relevance to the needs of new immigrants. There will be 4-10 participants in the study. Eligible participants must be from one of the following four categories. First, employee of Citizenship and Immigration Canada who works in Host Program department of the Settlement branch. Second, employee of the Service Providing Organizations which provides, among other settlement services, Host Program services to newcomers and who works in Host Program department. Third, Canadian resident who provided Host services to newcomers. Fourth, immigrants who received Host Program services.

\section{Description of the Study:}

You will be asked to answer a list of interview questions that are related to your experiences with Host Program and receiving Host Program services. Interviews will be scheduled to take place in a private and quiet setting chosen in agreement with you. For example, Ryerson ISS private graduate study room or private study room at your local library can be used as a private location. I will ensure your privacy, anonymity and confidentiality when carry out the research. The interview will also be conducted according to your schedule, to ensure that there will be no 
interruption in your daily routine. Each interview is scheduled to take between 60 to 90 minutes depending on how much in detail you are willing to share with me.

\section{What is Experimental in this Study:}

None of the procedures used in this study are experimental in nature. The only experimental aspect of this study is the gathering of information for the purpose of analysis.

\section{Risks or Discomforts:}

For Host volunteers and newcomers - in case, when experience related to receiving or providing Host Program services was negative or unsatisfactory participants may feel uncomfortable when recalling unpleasant experiences while answering the interview questions. For $\mathrm{CIC}$ and SPO representatives - due to the nature of their work which requires promotion and advertising of Host Program, $\mathrm{CIC}$ and SPO employees may feel uncomfortable when answering questions related to weaknesses and problems of Host Program. If at any point during the interview, you happen to feel discomfort with the interview questions, you are able to exit the study at any time without providing any reason for doing so.

\section{Benefits of the Study:}

There will be no direct benefit to you. The main objective of this study is to develop recommendations on the delivery of Host Program to newcomers based on existing problems and challenges that are hindering its effectiveness. As a result, provision of Host Program can be improved and available to more immigrants which might entail social inclusion of more immigrants into Canadian society.

\section{Confidentiality:}

Interview will be confidential and the content will be tape recorded and notes will be taken. All of the interview data will be kept confidentially in a place where only I will have access to. Also, I will be the only person who will be transcribing from tape recordings. The recordings will be stored for one year following the submission of the study. They will be stored in a filing cabinet with a lock that only I have a key to, in my apartment.

\section{Incentives to Participate:}

Participant will not be paid to participate in this study.

\section{Costs and/or Compensation for Participation:}

There will be no cost involved in this study. 


\title{
Voluntary Nature of Participation:
}

Participation in this study is voluntary. Your choice of whether or not to participate will not influence your future relations with Ryerson University. At any particular point in the study, you may refuse to answer any particular question or stop participation altogether.

\section{Questions about the Study:}

If you have any questions about the research now, please ask. If you have questions later about the research, you may contact.

\author{
Zebiniso (Nisa) Abduvaitova \\ 416-710-7822 \\ zabduvai@ryerson.ca
}

If you have questions regarding your rights as a human subject and participant in this study, you may contact the Ryerson University Research Ethics Board for information:

Research Ethics Board c/o Office of the Vice President, Research and Innovation Ryerson University 350 Victoria Street Toronto, ON M5B 2K3 416-979-5042

\section{Agreement:}

Your signature below indicates that you have read the information in this agreement and have had a chance to ask any questions you have about the study. Your signature also indicates that you agree to be in the study and have been told that you can change your mind and withdraw your consent to participate at any time. You have been given a copy of this agreement.

You have been told that by signing this consent agreement you are not giving up any of your legal rights. 
By signing the following section, I agree that the interview will be audio recorded. 


\section{Appendix 3}

\section{Interview Questions}

\section{Questions for SPO representatives}

1. How do you evaluate the effectiveness of the Host Program in the adaptation and integration of newcomers into Canadian society?

2. What are the main factors that distinguish this program from other settlement services?

3. What is the most beneficial aspect of the Host program for newcomers?

4. How do you think this program benefits volunteers?

5. Is there a demand for this program among your clients? How long is your waitlist?

6. What are the biggest problems in delivering this program for your SPO?

7. How do you promote the Host Program among your clients?

8. Is it effective in attracting newcomers?

9. What can be improved in the promotion of the Host Program among newcomers?

10. How do you promote the Host Program among Canadians? is it effective in attracting Canadian volunteers? What can be done in order to attract as many Canadian volunteers as possible?

11. What are the biggest challenges in attracting Host volunteers? How it can be improved?

12. What do you think is the main motivation for volunteers to join this program?

13. How do you motivate volunteers to remain in the program?

14. What are the main positive effects of the Host Program for newcomers? For volunteers?

15. Do you think that the Host Program is effective in building networks between Canadian society and newcomers?

16. Do you think it will be beneficial for both Canadians and immigrants if the Host Program is expanded to the extent that most immigrants will receive Host services upon arrival? Why?

17. What other recommendation would you give for improving the effectiveness of the Host Program delivery to newcomers?

\section{Questions for Host volunteers}

1. How did you learn about the Host Program? Why you are doing this? What is your motivation?

2. What kind of activities do you do with your match? How often do you meet? Where?

3. Do you introduce your newcomer match to your network of friends?

4. Do you think the Host Program really helps newcomers to integrate better? Why?

5. In what ways does the Host Program help newcomers to integrate?

6. Do you keep in touch with your match after completing the required time in the program? 
7. How often do you think host-volunteer relationships turn into friendships?

8. What kind of benefits do you see in the Host Program for newcomers?

9. Are there any benefits for host-Canadians? Specifically for you?

10. What was/were the biggest challenge(s) in your interactions with newcomers?

11. What do you think are the biggest integration issues newcomers have?

12. Do you think current promotion of the Host Program is effective in attracting volunteers? What do you think can be changed and improved in the promotion of the Host Program among Canadians?

13. What, in your opinion, are the main strengths of this program?

14. What are the main weaknesses?

15. Do you think it will be beneficial for both Canadians and immigrants if the Host

Program is expanded to the extent that most immigrants will receive Host services upon arrival? Why?

16. What other recommendations would you make in order to improve the effectiveness and results of the Host Program?

\section{Questions for newcomers who received the Host Program services}

1. How did you learn about the Host Program?

2. Where do you meet?

3. What do you do with your host match?

4. Does your host introduce you to his/her friends?

5. Does this program help you to make new friends?

6. What is your biggest difficulty in adapting to Canadian life?

7. How does the Host Program help you in adapting to your new country?

8. What do you think can be changed and improved in promotion of the Host Program among new immigrants?

9. What were the positive effects of the Host Program on your adaptation to life in Canadian society?

10. What aspects of your adaptation to Canadian life were impacted most by the Host Program?

11. Do you still maintain contact with your host?

12. Do you think your networks were expanded after receiving the Host Program services?

13. In your opinion, what are the weaknesses of the Host Program?

14. What are the strengths of the Host Program?

15. What did you like most in your experience with the Host Program? Why?

16. What did you like least in your experience with Host Program? Why?

17. Do you think it will be beneficial for both Canadians and immigrants if the Host Program will be expanded to the extent that most immigrants will receive Host services upon arrival? Why?

18. What other recommendations would you give to improve the effectiveness of the Host Program delivery to newcomers? 


\section{References}

Anisef, P. et al., (2005) Issues confronting newcomer youth in Canada: alternative models for a national youth Host Program. CERIS Working Paper No. 39.

Axiom Consultants Inc and Stiles Associates Inc (2009) Draft Planning, Monitoring \& Reporting Strategy \& Tools for the Host Program in Ontario. 1-8.

Baldacchino, G., et. al. 2009. The Host Program and Immigrant Retention on Prince Edward Island. A Pilot Project supported by the 2008-2009 Atlantic Metropolis Grant Competition. Published by University of Prince Edward Island.

Beugelsdijk, S. and Smulders, S. (2003) Bridging and Bonding Social Capital: Which type is good for economic growth? Paper submitted to ERSA Jyvaskila (Finland). Tilburg University Center/Faculty of Economics. pp. 1-36.

Biles, J., Burstein, M., Frieders, J. (2008) Introduction. In Biles, J., Burstein, M., Frieders, J. (Eds.), Immigration and Integration in Canada in the Twenty-first Century.School of Policy Studies, McGill-Queen's University Press. 1-19.

Biles, J., Winnemore, L. (2006) Canada's two-way street integration model without its stains, strains and growing pains. Canadian Diversity, Vol. 5 (1) 47-66.

Biles, J. (2008). Integration Policies in English Speaking Canada. In Biles, J., Burstein, M., Frieders, J. (Eds.), Immigration and Integration in Canada in the Twenty-First Century. School of Policy Studies, McGill-Queen's University Press. 139-186.

Bloemraad, I. (2006) Structured Mobilization: The role of Government in Becoming a Citizen: Incorporating Immigrants and Refugees in the United States and Canada. University of California Press Ltd. 103-137.

Caidi, N., and Allard, D. (2005) Social Inclusion of Newcomers to Canada: An Information Problem? CERIS No. 23, Policy Matters, December 2005.

Costi.org website. Programs and Services; Host Program http://www.costi.org/programs/program details.php?program id=196

Citizenship and Immigration Canada. Be a Host to a Newcomer. http://www.cic.gc.ca/english/department/partner/canadian-host.asp

Citizenship and Immigration Canada. 2004. Evaluation of Host. http://www.cic.gc.ca/english/resources/evaluation/host/findings.asp 
Citizenship and Immigration Canada. 2007. Audit of Immigration. Final Report. http://www.cic.gc.ca/EnGLIsh/resources/audit/icams.asp

Citizenship and Immigration. 2007. Welcome to Canada brochure. http://www.cic.gc.ca/EnGLish/pdf/pub/welcome.pdf

Citizenship and Immigration Canada 2010.

http://www.cic.gc.ca/english/resources/publications/welcome/wel-03e.asp\#linc

Citizenship and Immigration Canada 2010.

http://www.cic.gc.ca/english//resources/evaluation/isap/exec-summary.asp\#s4\%20ids4

Florida, R. (2002). The rise of the creative class. And how it's transforming work, leisure and everyday life. New York: Basic Books.

Galabuzi, G. E., Teelucksingh, C. (2010). Social Cohesion, Social Exclusion, Social Capital. Discussion Paper funded by CIC. 1-44.

George, U., Chaze. F. (2009) Tell me what I need to know: South Asian Women, Social Capital and Settlement. International Migration and Integration, 10, 265-282.

George, U., and Fuller-Thomson, E. (1997). To Stay or Not to Stay: Characteristics Associated With Newcomers Planning to Remain in Canada. Canadian Journal of Regional Science. Spring-Summer. 181-194.

George, U. (2002). A Needs-Based Model for Settlement Service Delivery for Newcomers to Canada. International Social Work 2002; 45; 465-480.

George, U., et al (2004). Recommendations for the Delivery of ISAP Services to Mandarin Speaking Newcomers from Mainland China. Final Report for CERIS. pp. 1-45.

HostOntario.org website http://www.hostontario.org/e/index.cfm

HostOntario.org. Ontario Host Program Conference. October 2007. http://www.hostontario.org/files/HostConference10-07 Summary.pdf

HostOntario.org. Ontario Host Program Conference. March 2008. http://www.hostontario.org/files/Report-HostConferenceMarch\%202008.pdf

HostOntario.org. Ontario Host Program Conference. February 2009.

http://www.hostontario.org/e/publication_detail.cfm?doid=284

HostOntario.org. Consultations with Host Program Participants. 2008.

http://www.hostontario.org/e/publication detail.cfm?doid=287 
Integration Branch of CIC (2001) Immigrant Integration in Canada: Policy Objectives, Program Delivery and Challenges. Draft for discussion. 1-36. Retrieved from http://atwork.settlement.org/sys/atwork library detail.asp?passed lang=EN\&doc id=1 $\underline{003190}$

Kerr, G., and Powers, L. C. (2005) Review of Host Group Service Models in Ontario, Citizenship and Immigration Canada, Ontario Settlement Directorate. pp. 1-30.

Kelley, N., \& Trebilcock, M. (2000). The Making of the Mosaic: A History of Canadian Immigration Policy. Toronto: University of Toronto Press.

Kunz, J. L. (2003). Social Capital: A Key Dimension of Immigrant Integration. Canadian Issues: Immigration and the Intersections of Diversity. Ed. M. Burstein. Montreal: Association for Canadian Studies. 33-34.

Kunz, J. L. (2005). Orienting newcomers to Canadian society: Social capital and settlement. Policy Research Initiative. Unpublished discussion paper.

st

National Settlement Conference II (2003). Community Building Strategies for the 21 Century: Innovation, Inclusion and Partnership. Calgary, Alberta.

Neuman, W., L. (2006) Social Research Methods: qualitative and quantitative approach. $6^{\text {th }}$. ed. Pearson Education, Inc.

Omidvar, R. And Richmond, T. (2003). Immigrant settlement and social inclusion in Canada. In Richmond, T. And Saloojee, A. (Eds) Social inclusion Canadian Perspective. Laidlaw Foundation. Fernwood Publishing. pp. 155-179.

Policy Research Initiative (2003). Social Capital: Building on a Network Based approach. Draft Discussion paper for PRI Project: Social Capital as a public policy tool. 1-31.

Ritchi, J., Lewis, J. (2003) Qualitative research practice. A guide for social science students and researchers. London, Thousand Oaks: Sage.

Siemiatycki, M. (2005) From social exclusion to Social inclusion: Conceptual and Policy Approaches. Social Development Canada, 2005.

Shields, J. (2007). Mobilizing Immigration Research for Policy Effect: The Case of CERIS. CERIS Working Paper 58 (June 2007): 1-30. 